\title{
Transvenous Coil-plugging Technique for a Symptomatic Giant Varix Associated with Arteriovenous Malformation
}

\author{
Yuji KushI, ${ }^{1}$ Tetsu SATOw, ${ }^{1}$ Taichi IKEDO, ${ }^{1}$ Tsuyoshi OHTA, ${ }^{1}$ Takeshi Hara, ${ }^{1}$ \\ Jun C. TAKAHASHI, ${ }^{1}$ Koji IIHARA, ${ }^{1}$ and Hiroharu KATAOKA ${ }^{1}$
}

${ }^{1}$ Department of Neurosurgery, National Cerebral and Cardiovascular Center, Suita, Osaka, Japan

\begin{abstract}
In case of symptomatic varix associated with cerebral arteriovenous malformations (AVM), nidus is usually treated with transarterial embolization (TAE). However, TAE is not always possible due to inaccessible nidus. A man in his 40s presented with numbness and clumsiness in the right hand. Magnetic resonance imaging (MRI) and cerebral angiography revealed a giant varix associated with an AVM nidus in the left parietal lobe. The varix severely compressed the postcentral gyrus with edema. The main feeder was occluded, and tiny collateral vessels fed the nidus. After admission, his symptoms deteriorated rapidly due to the enlarging varix. To extirpate the varix, selective transvenous embolization (TVE) of a small compartment, the varix neck, between the varix and the main cortical drainer with coils was performed. After treatment, the thrombosed varix gradually shrank, and his symptoms improved. The transvenous coil-plugging technique is a potential strategy for symptomatic varix with a varix neck.
\end{abstract}

Keywords: arteriovenous malformation, varix, transvenous embolization

\section{Introduction}

Varix is often associated with cerebral arteriovenous malformations (AVM). ${ }^{11}$ As it contributes to the development of bleeding or mass effect, nidus is usually treated with direct surgery or stereotactic radiosurgery with or without endovascular techniques. ${ }^{2-4)}$ However, therapeutic interventions targeting a varix itself are uncommon because unexpected interruption of the drainage route can cause rupture of the nidus. Here, we report a rare case of transvenous treatment of a giant varix.

\section{Case Report}

A man in his 40s presented with numbness and clumsiness in the right hand. Magnetic resonance imaging (MRI) revealed an AVM with a maximum diameter of $34 \mathrm{~mm}$ in the left parietal lobe (Fig. 1). The AVM was accompanied by a partially thrombosed

Received December 25, 2020; Accepted February 22, 2021

Copyright $@ 2021$ The Japan Neurosurgical Society This work is licensed under a Creative Commons AttributionNonCommercial-NoDerivatives International License. giant varix with a maximum diameter of $26 \mathrm{~mm}$. The varix severely compressed the postcentral gyrus with edema. There were no findings of previous bleeding. Angiography showed that the nidus was fed by the left middle cerebral artery (MCA), the left anterior cerebral artery, and the posterior cerebral artery (Fig. 2). The main feeder from the MCA was occluded just distal to the MCA bifurcation and was accompanied with tiny collateral vessels. The varix was on the side wall of a main cortical drainer flowing into the superior sagittal sinus (SSS). A small compartment with a maximum diameter of $14 \mathrm{~mm}$, a varix neck, was located between the drainer and the varix (Fig. 2). Although the patient was initially treated conservatively, his symptoms deteriorated rapidly due to enlargement of the varix to a maximum diameter of $33 \mathrm{~mm}$ in 5 days after admission. For urgent relief of compression from the enlarging varix, we planned selective transvenous embolization (TVE) for only the varix neck to avoid possible mass effects by massive coils in the whole varix.

Under general anesthesia, a 7-cm 6-Fr sheath (Terumo, Tokyo, Japan) was inserted into the left jugular vein. For contrast medium injection, two 4-Fr catheters (Gadelius Medical, Tokyo, Japan) were placed in the left internal carotid artery and the 


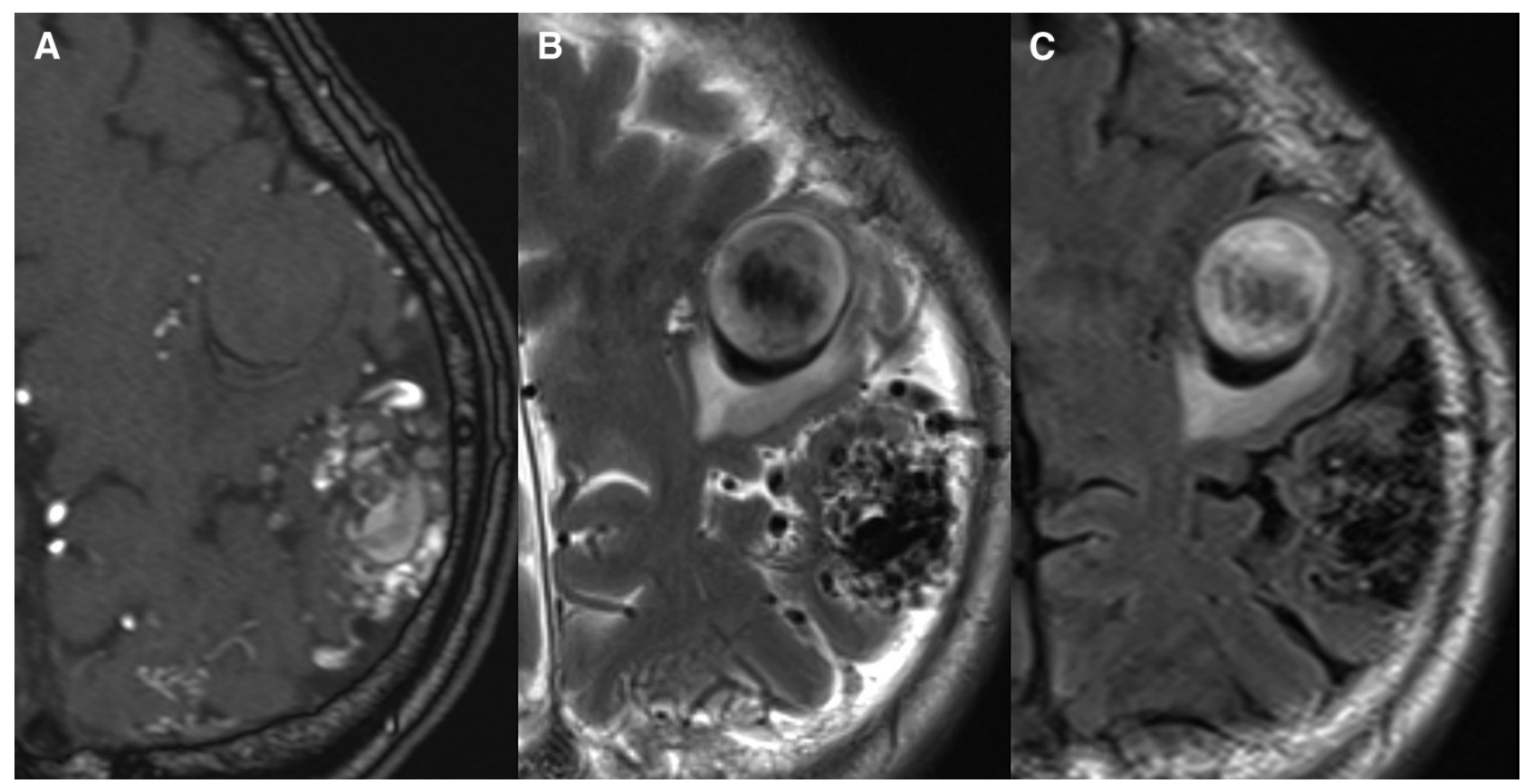

Fig. 1 MRA on admission revealed a nidus and a varix in the left parietal lobe (A). T2WI (B) and FLAIR (C) showed a partially thrombosed varix with edema in the postcentral gyrus, but no previous bleeding. FLAIR: fluid-attenuated inversion recovery, MRA: magnetic resonance angiography, T2WI: T2-weighed image.

left vertebral artery, respectively, through bilateral transfemoral sheaths. After systemic heparinization, a guide catheter (6-Fr FUBUKI; Asahi Intecc, Aichi, Japan) was inserted into the SSS. To embolize with the double catheter technique, one microcatheter (Phenom 17; Medtronic, Minneapolis, MN, USA) was advanced into the inferior part of the varix neck, and another microcatheter (SL-10; Stryker, Kalamazoo, MI, USA) was advanced into the superior part. The size of varix neck was $14 \times 8 \times 7 \mathrm{~mm}$. At first, we had difficulty in forming a cage only in the varix neck due to the wide frontage of the varix and the varix neck. Therefore, two large coils (Axium PRIME Frame $10 \mathrm{~mm} \times 30 \mathrm{~cm}$ [Medtronic] and Target XL 360 Standard $12 \mathrm{~mm} \times 45 \mathrm{~cm}$ [Stryker]) were advanced from SL-10 and Phenom 17, respectively, to form a scaffold in the proximal part of the varix and the varix neck by double catheter technique. After making a stable scaffold with a few more coils, smaller and soft coils such as Axium Prime 3D (Medtronic), i-ED (KANEKA CORPORATION, Tokyo, Japan) coils from Phenom 17 were added to fill inside the varix neck, with the SL-10 repositioned into the varix to ensure access to the varix neck in case of unintended withdrawal of the Phenom 17. The inferior part was embolized using the Phenom 17, and then the residual small superior space was embolized using deeply positioned SL-10 with careful pullback. After placing 31 coils, blood flow into the varix was eliminated with faint opacification of the varix neck (Fig. 3).

The patient had one partial seizure in the right arm on the day after treatment, and his symptoms disappeared within 1 month except for slight numbness in the right hand. Cerebral angiography 5 days after treatment showed complete occlusion of the varix. The nidus was treated with gamma knife surgery with a marginal dose of 20 Gy 28 days after the procedure. Follow-up MRI revealed thrombosis and gradual shrinkage of the varix (Fig. 4).

\section{Discussion}

A giant varix associated with AVM sometimes causes a symptomatic mass effect. ${ }^{1,2)}$ Although there is no consensus on the optimal treatment for symptomatic varices, previous reports indicated that transarterial embolization (TAE) for nidus was effective to achieve disappearance or flow reduction of varices. ${ }^{2,3)}$ However, there have been only a few reports of nidus excision due to varix enlargement resulting from incomplete $\mathrm{TAE}^{5)}$ and foreign body reaction by embolic materials. ${ }^{6)}$

In the present case, rapidly worsening symptoms required urgent treatment to reduce the mass effect of the enlarging varix. Therapeutic strategies, such as TAE for the nidus, surgical resection of the nidus, were considered unfavorable for several 


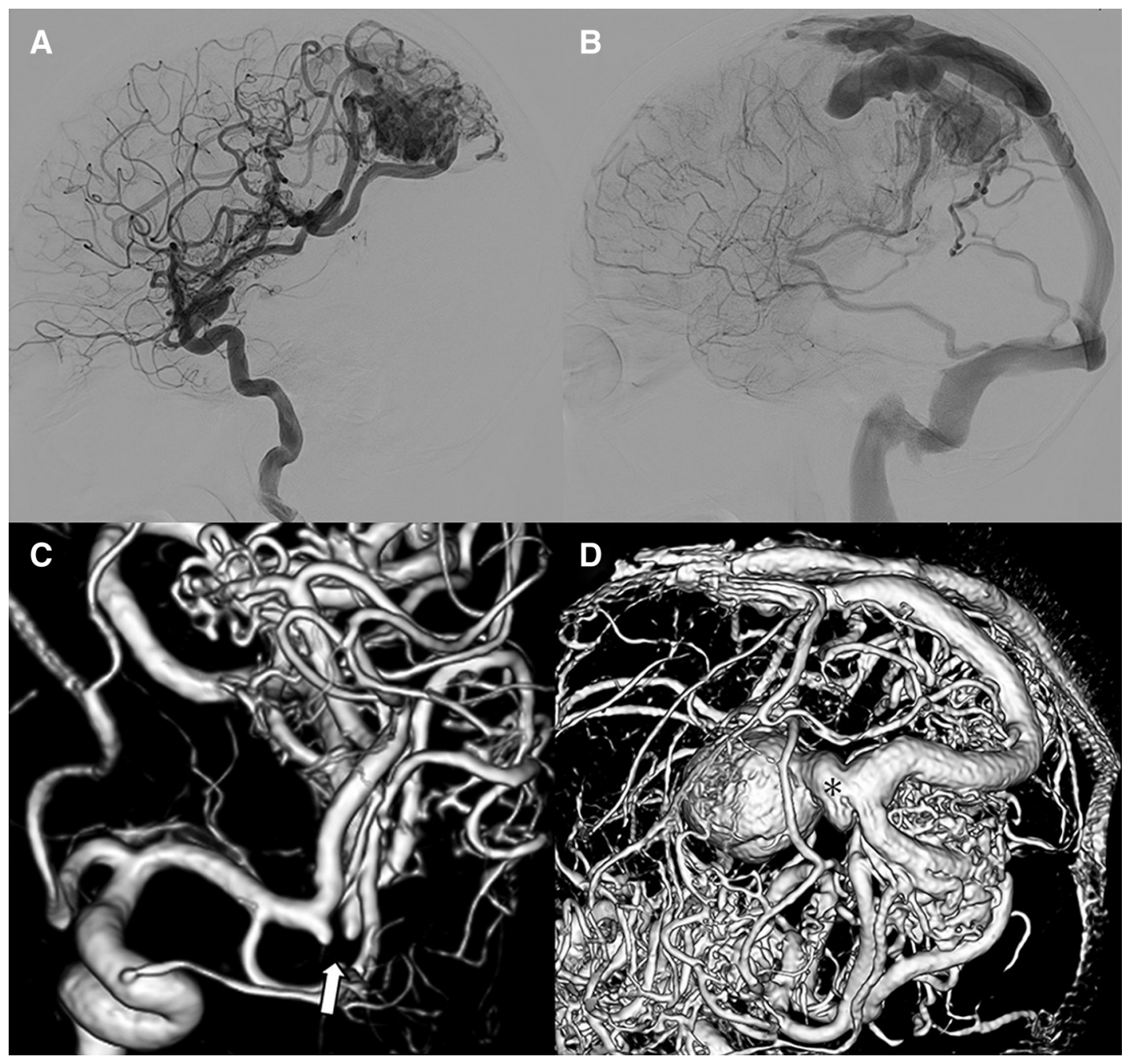

Fig. 2 Initial left internal carotid angiograms (lateral view). (A) Arterial phase. (B) Venous phase. (C) 3D rotational angiography. The nidus was fed mainly by the MCA and the varix was located anterior to the nidus. The main feeder from the MCA was occluded just distal to the MCA bifurcation and accompanied with tiny collateral vessels (white arrow). (D) 3D rotational angiography (venous phase) showed enlargement of the varix. A small compartment, the varix neck (asterisk), was located between the varix and a cortical vein draining into the SSS. MCA: middle cerebral artery, SSS: superior sagittal sinus, 3D: three-dimensional.

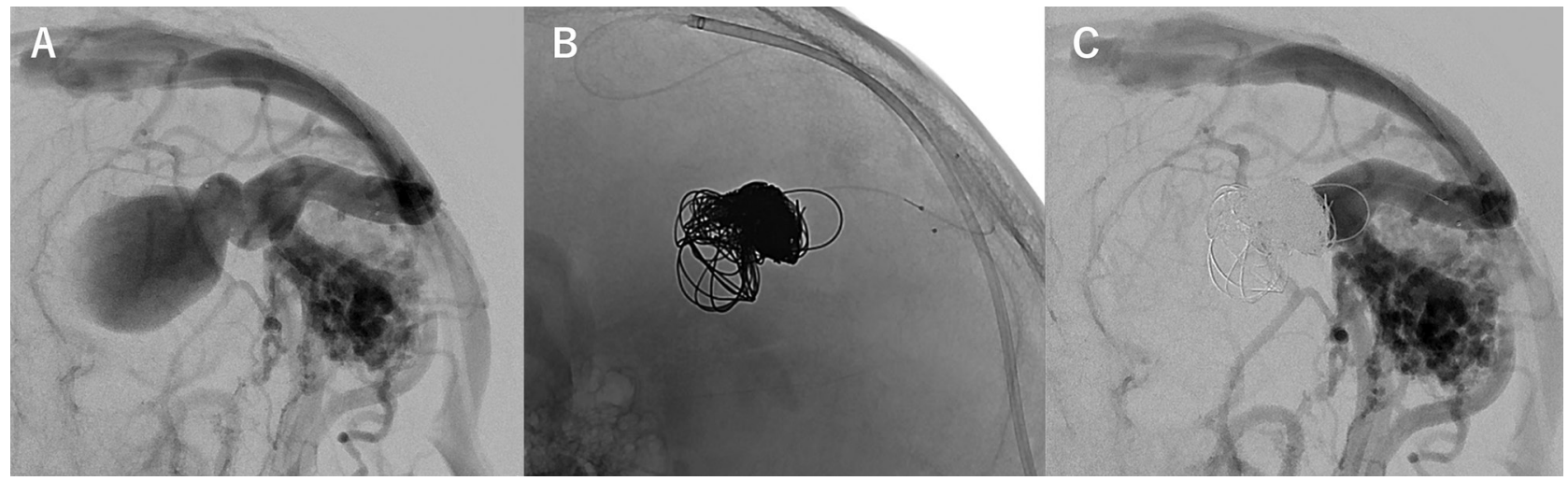

Fig. 3 (A) Left internal carotid angiogram showing insertion of two microcatheters into the varix neck. (B) Coils were tightly packed in the varix neck with the double catheter technique. (C) After coil embolization, blood flow into the varix disappeared. 


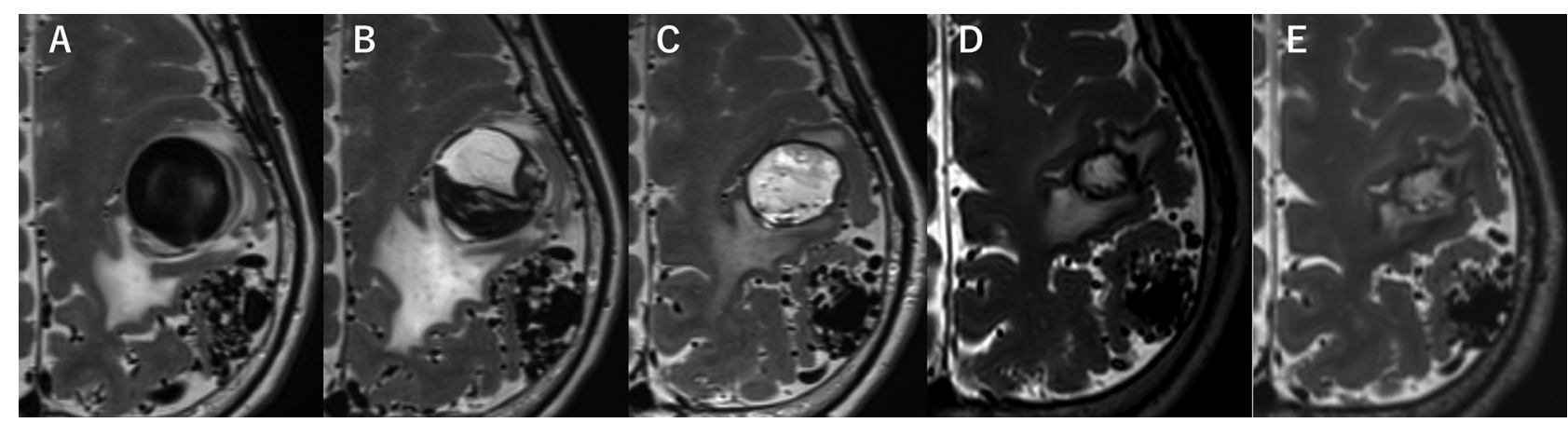

Fig. 4 Heavy T2WI before treatment (A), POD6 (B), POM1 (C), POM3 (D), and POM6 (E) showed gradual shrinkage and thrombosis of the varix and improvement of edema in the peri-varix gyrus. T2WI: T2-weighed image.

reasons. As for TAE described in previous reports, ${ }^{2,3}$ occlusion of the main feeder prevented the microcatheter approaching close to the nidus via the transarterial route in this case. TAE from the proximal part of the occlusion or other feeders also had a risk of infarction due to occlusion of collateral vessels that may be perfusing normal tissues. As the nidus was in the left angular gyrus, surgical resection could cause postoperative Gerstmann syndrome. Surgical interruption of the varix or selective TVE for the varix was considered favorable to prevent from such complications, although injury to the main drainer may cause obstruction of the draining route and severe hemorrhagic events. After discussion among neurosurgeons and neuroendovascular physicians, selective TVE for the varix itself was considered safer, and adopted in the present case. However, packing of the varix with massive coils is associated with a risk of additional mass effects. With the unique structure of the varix in our case, a small compartment, a varix neck, was interposed between the varix and the drainer. Based on recent treatments for large cerebral aneurysms with flow diverters, ${ }^{7)}$ we planned a strategy involving blocking flow into the varix with transvenous plugging of the varix neck. This innovative technique and unique architecture of the varix enabled us to achieve a good outcome. At 6-month follow-up, the varix was thrombosed and shrank. However, long-term follow-up will be necessary as recanalization due to coil compaction may take place.

Regarding antithrombotic therapy, intraprocedural systemic heparinization was the only regimen carried out in this case because the main drainer was large in diameter, and the risk of obstruction was considered low.

As to the transvenous approach for treating cerebral AVMs, radical TVE of the whole nidus has been reported recently, ${ }^{8)}$ there have been no reports of selective TVE targeting the symptomatic varix as described here.

Spontaneous occlusion of the main feeder of AVM is also a rare phenomenon. Enam et al. reported obstruction of a major feeder in 7 of 500 AVM cases $(1.4 \%) .{ }^{9)}$ Although the mechanism has not been fully elucidated, a high-flow shunt is assumed to cause hemodynamic insults against the feeding vessel walls, leading to occlusion or severe stenosis. ${ }^{10)}$ In this case, main feeder occlusion may have affected the clinical course of the varix. It is speculated that the varix was formed by hemodynamic stress of high-flow feeder at first. Secondary, gradual occlusion of main feeder caused stagnation of blood flow followed by thrombosis in the varix.

Similarly with the mechanism in thrombosed, giant intracranial aneurysms, inflammatory change mediated by the thrombus in the varix may result in its enlargement. ${ }^{11)}$

Here, we reported successful treatment of symptomatic giant varix with the TVE due to inaccessible AVM nidus via the transarterial route. To avoid coil mass effect, the varix neck was selectively plugged with a transvenous coil-plugging technique. This technique is a potential strategy for symptomatic varix with a varix neck.

\section{Conflicts of Interest Disclosure}

Dr. Kushi, Dr. Ikedo, Dr. Hara, Dr. Takahashi, Dr. Iihara, and Dr. Kataoka declared no potential conflicts of interest with respect to the research, authorship, and/or publication of this article.

Dr. Satow reports research funding from Canon Medical Systems corp., outside the submitted work.

Dr. Ohta reports personal fees from Stryker, personal fees from Terumo, personal fees from Kaneka, personal fees from Medtronic, personal fees from Nipro, personal fees from Medicos Hirata, 
personal fees from Century Medical, outside the submitted work.

\section{References}

1) D’Aliberti G, Talamonti G, Cenzato M, et al.: Arterial and venous aneurysms associated with arteriovenous malformations. World Neurosurg 83: 188-196, 2015

2) Li G, Wang G, Yu J, Hou K, Yu J: Regression of a symptomatic varix after transarterial embolization of a brain arteriovenous malformation: a case report and literature review. Medicine (Baltimore) 98: e18418, 2019

3) Chakraborty S, Eldridge P, Nahser HC: Cerebral haemorrhage from a remote varix in the venous outflow of an arteriovenous malformation treated successfully by embolisation. Br J Radiol 83: 129-134, 2010

4) Ishikawa T, Houkin K, Sawamura Y, Aoyama T, Abe $\mathrm{H}$ : Brain stem arteriovenous malformation with large venous varix. J Stroke Cerebrovasc Dis 8: 94-98, 1999

5) Mineura K, Sasajima H, Itoh Y, Kowada M, Tomura N, Goto K: Development of a huge varix following endovascular embolization for cerebellar arteriovenous malformation. A case report. Acta Radiol 39: 189-192, 1998

6) Haryu S, Endo H, Endo T, Sato K, Fujimura M, Tominaga T: Growth of thrombosed cerebral venous varix following resection of cerebral arteriovenous malformation: case report with pathologic consideration. World Neurosurg 119: 274-277, 2018

7) Lylyk P, Miranda C, Ceratto R, et al.: Curative endovascular reconstruction of cerebral aneurysms with the pipeline embolization device: the Buenos Aires experience. Neurosurgery 64: 632-642; discussion 642-643; quiz N6, 2009

8) Nguyen TN, Chin LS, Souza R, Norbash AM: Transvenous embolization of a ruptured cerebral arteriovenous malformation with en-passage arterial supply: initial case report. J Neurointerv Surg 2: 150-152, 2010

9) Enam SA, Malik GM: Association of cerebral arteriovenous malformations and spontaneous occlusion of major feeding arteries: clinical and therapeutic implications. Neurosurgery 45: 1105-1111; discussion 1111-1112, 1999

10) Pile-Spellman JM, Baker KF, Liszczak TM, et al.: High-flow angiopathy: cerebral blood vessel changes in experimental chronic arteriovenous fistula. AJNR Am J Neuroradiol 7: 811-815, 1986

11) Atlas SW, Grossman RI, Goldberg HI, Hackney DB, Bilaniuk LT, Zimmerman RA: Partially thrombosed giant intracranial aneurysms: correlation of MR and pathologic findings. Radiology 162: 111-114, 1987

Corresponding author: Tetsu Satow, MD, PhD Department of Neurosurgery, National Cerebral and Cardiovascular Center, 6-1 Kishibeshimmachi, Suita, Osaka 564-8565, Japan. e-mail: tetsus@ncvc.go.jp 